\title{
The incentives may not be the incentive: a field experiment in recycling of residential food waste
}

\author{
C. Lia; Y. Wanga; Y. Lia; Y. Huanga; M.K. Harder ${ }^{\mathrm{b}, \mathrm{a}^{*}}$
}

a Department of Environmental Science and Engineering, Fudan University, 2205 Song Hu Road, Shanghai 200438, PR China

b University of Brighton, Cockcroft Building, Lewes Road, Brighton BN2 4GJ, UK

Corresponding author: m.k.harder@brighton.ac.uk

\begin{abstract}
Recycling of residential food waste is urgently needed in cities worldwide to mitigate issues of greenhouse gases, pollution, and resource wastage. Poor waste-sorting behaviour of residents is a key barrier: academics put forward general principles for behaviour change, but none resulting in successful large-scale and effective recycling programs. The complexity of factors influencing this behaviour has historically made the development of prescriptive theories - theories which can predict useful program interventions for a range of situations- impossible. Here we present our sixth study in a research-through-design series to develop a general prescriptive theory of residential recycling behaviour. We used five residential compounds in modern China (and controls) to experimentally test the impact of suspending household 'Incentives' on recycling tonnages, while varying 'Social Influences'. The results confirmed these as causal determinants, alongside 'Habit', which was found well-formed after 12 months. The relative determinant influences in months $10-$ 11 (months 14-23) were: habit 50\% (80-90\%); social influences 50\% (10-20\%); incentives $12 \%(5 \%)$. Surprisingly, 'Social Influences' dominated 'Incentives'. Exploratory interviews indicated that Interpersonal Interactions comprised an important element of 'Social Influences'. In addition, 10-20\% participants were inconvenienced by the time-window imposed for depositing their food waste. These two factors deserve more careful consideration by planners, and testing in the Prescriptive Theory-building.
\end{abstract}

Keywords: empirical prescriptive theory; incentives; social influences; recycling; inconvenience; food waste. 


\section{Highlights}

- Developing a prescriptive theory of residential recycling behaviour

- Causality confirmed for Incentives, Social Influences and Habit

- 'Social Influences' dominated 'Incentives' 3:1, contrary to design

- 'Inconvenience' at $10-20 \%$ was unexpectedly revealed

- Several direct policy recommendations 


\section{Introduction}

Municipal solid waste is an acute problem worldwide, especially in dense urban areas where land is less available and huge waste volumes accumulate linearly rather than being re-circulated in material or energy resource cycles. In countries such as China, landfilling (57\%) and incineration (40\%) are the two main waste management techniques (EPA, 2019), but the sub-fraction of food waste is particularly problematic as it contains around $65 \%$ water (Zhuang et al., 2008). In incinerators fossil fuels need to be added to 'burn' such wet waste (Cheng and $\mathrm{Hu}, 2010$ ), and in landfills it produces much methane and leachate (Zhang et al., 2010). If diverted appropriately, food waste could instead be converted into biogas and/or soil enhancers.

The governments of mega-cities in China are determined to find solutions to these problems, and have already heavily invested in infrastructure and facilities (Huang et al., 2014). However, a vital yet weak link to successful residential recycling, and especially food waste recycling, has long been known to be the cooperation of residents to sort their waste at the household level. The only published solutions to this problem have been small-scale or time-limited, (other than a rare case presented from Nanjing recently (Li et al., 2017) which is financially burdensome).

The current academic literature on recycling does not offer clear advice to policy makers or practitioners for designing residential recycling programs. There are many wellestablished descriptive theories which can relate their constructs to self-reported performance, but they are not prescriptive theories (Christensen and Raynor, 2003; Carlile and Christensen 2006; Christensen and Carlile 2009), i.e. linked to behaviour and able to prescribe actions for predictable measured results in different circumstances as found in the field. However, a prescriptive theory is what city planners urgently need (Allcott and Mullainathan, 2010; Eppel et al., 2013; Steg and Vlek 2009) and is the motivation for our research. Readers might note that such prescriptive theories can be entirely derived from grounded results which are not based on any theories: as long as those grounded results can build a model or typology of determinants, which then develops into a theory to produce prescriptive interventions for different circumstances. Such a grounded approach underpins this work, which is a continuation of a series of linked independent investigations (Dai et al., 2015; Dai et al., 2016; Xu et al., 2016; Lin et al., 2016; Huang et al., 2018) carried out in collaboration with various government bodies of Shanghai Municipality and part-funded by 
them. They contribute to the incremental development of a robust, empirically grounded Prescriptive Theory of Residential Waste Recycling behaviour, with which we can provide practical advice to city planners, not only in China but in other circumstances.

There are two main stages to this theory building, as illustrated in the schematic diagram in Figure 1. First, the triangle on the left shows that observable measurable phenomena should be explored, and any attributes of them which are thought to be correlated to the desired outcome - improved recycling performance - be iteratively identified and selfcategorised via abductive cycles of induction and deduction. This research-through-design process (Frayling, 1993; Archer, 1995) can ultimately reveal a typology: a grounded 'model' or framework of determinants which are thought to be correlated to recycling performance. No causality is implied at this stage.

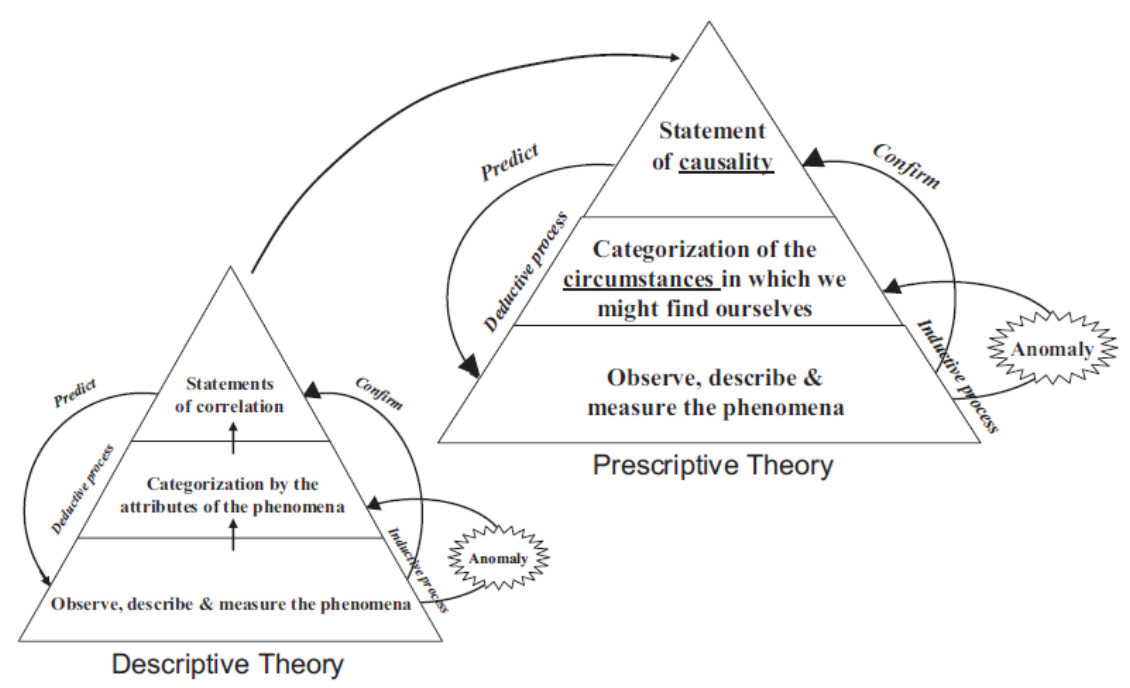

Figure 1. A framework for theory building.

(Adapted from Christensen and Carlile, 2009. It consists of development stages of Stage 1, Descriptive Theory, and Stage 2, Prescriptive Theory, linked by a Transition, where the two types of categorization iteratively define each other during model development.)

We have previously carried out several Stage 1 studies (e.g. Dai et al., 2015; Xu et al., 2016), and we will build on those results here.

In some fields of research, Stage 1 studies can produce a finely-honed typology before 
moving on to trials of them in Prescriptive Stage 2 under different categories of circumstances. For example, parameters of a chemical reaction for combustion, which can then be trialled in different complex incinerator scenarios where other contaminant gases are present. However, for residential recycling in general, and food waste sorting in particular, it is notoriously difficult to identify the specific attributes of phenomena which are crucial, and the only way to narrow this down is to promptly consider candidates in an exploratory Stage 2 under different 'categories of circumstances' - which can themselves only be better-defined when this is done in sync with different iterations of the attributes of phenomena from Stage 1. For example, residents might be given small bins for their kitchens where they can divert food waste, but they have several attributes which might be determinants to increased sorting, such as convenience, colourful prompting, emotional response to the 'gift', and whether it is easy to keep clean: there is no obvious shortlist of possibilities. But if different kitchen bins are given out in different circumstances, including (among other variable aspects) large houses and small apartments, then correlations against recycling performance alongside explorative interviews might suggest that their size, or size relative to the kitchen, could be crucial attributes, and thus the range of potentially important attributes is narrowed. In other words, many cycles of iterations between the two main Stages will be expected, before culmination in a stable Stage 1 Typology, and then a Stage 2 Prescriptive Theory which is applicable in different circumstances.

Five of our previous studies (Dai et al., 2015; Xu et al., 2016; Dai et al., 2016; Lin et al., 2016; Huang et al., 2018) were each carefully designed for a specific theory-building focus in Stage 1, but several also revealed preliminary information about Stage 2, and Transitions to it, driving several iterative cycles. In aggregate, they resulted in the identification of several strong candidate-determinants, that are now ready for experimental testing in Stage 2 , which requires the use of a new category of circumstances.

The specific aim of the study reported here is to experimentally test the relative contributions of three of those candidate-determinants: Incentives, Habit, and Interpersonal Interaction. As with all of our studies, this latest one will simultaneously fulfil two objectives: to contribute to our mid-range Prescriptive Theory Building of residential recycling, and to perform a specific-range investigation, which in this case is the causality and interplay of the three determinants which are each of wider research interest. Both objectives are aligned with our overarching purpose of advising city planners on key design characteristics 
of upcoming recycling programs to be rolled out in Shanghai and Nanjing.

Below we provide an overview of recycling determinants and then a thorough literature review of the prior development of the theory-building, explaining how these three particular determinants require investigation. Then the methodology to do experimental testing is given, followed by the results, which include unexpected findings about a fourth determinant of Inconvenience. These are discussed and concluded with respect to the individual determinants, and their collective contribution to the prescriptive theory-building, and immediate implications for policy.

\section{General and specific literature review}

Readers can note that the foundation for this paper is not ad-hoc choice of the factors of Incentives, Habit and Interpersonal Interaction, but rather a clear logic developed through a systematic review and ongoing synthesis within the developmental stages of an empirical Prescriptive Theory of residential recycling. In 2.2 below we outline that logic. But for a wider context, we overview other research on those factors, in 2.1.

\subsection{Wider studies}

Many factors have been proposed to influence recycling behavior, including theory-based constructs, such as attitude (Tonglet et al., 2004; Refsgaard and Magnussen, 2009), norms (Hage et al., 2009; Barr et al., 2003), social influence (Abrahamse and Steg, 2013; Barr et al., 2003), and inconvenience (Perrin and Barton, 2001; Garcés, et al., 2002; Barr and Gilg, 2005). No overarching typology has been built from the scores of reported factors, but Geiger et al., (2019) did a meta-analysis of factors related to recycling and classified them into broadly individual and contextual factors. Individual factors included social norms, perceived behavioural control, personal norms, values, and anticipated affect. Contextual factors reflect the circumstances, and included local circumstances facilities in the neighborhood, the type of house. There are many descriptive theories developed to explain some aspects of recycling behaviour from different approaches, such as the Theory of Planned Behaviour (Ajzen, 1991), the Norm-Activation-Model (Schwartz and Howard, 1981), the Value-Belief-Norm theory on environmentalism (Stern, 2000), and AttitudeBehavior-Context Model (Guagnano, et al., 1995). More recently, human-computerinterface design has been applied, for example to develop ways to bridge the value-action 
gap portrayed by such models (Evans, 2014; Comber and Thieme, 2013).

Empirically, incentives delivered to households are known to sometimes attract the residents to initiate recycling, and can improve the participation rate quickly (Timlett and Williams, 2008; Harder and Woodard, 2007; Defra, 2007; Dahab et al., 1995). But incentives may not encourage more residents when the participation rate is high already (Harder and Woodard, 2007). However, reward schemes are often complex and it has been very difficult to isolate the effectiveness of the constituent parts (Timlett and Williams, 2008).

Social influence is another well studied family of factors: Abrahamse and Steg's (2013) meta-analysis suggest that social influence approaches are effective when compared to control groups. Studies involving block leaders, public pledges and behaviour modelling typically make use of face-to-face interaction, which may make social influence more powerful.

Inconvenience is seldom well-defined in theory or practice, but can refer to distance to the depositing site (Vencatasawmy et al., 2000), availability of relevant facilities (Perrin and Barton, 2001), scarce availability of time or space in the home (Garcés, et al., 2002), lack of space for recycling bins (Seonaidh and Caroline, 2003) and the time required (Perrin and Barton, 2001; Tonglet et al., 2004).

Habit is a factor that is sometimes ignored (Jackon, 2005), but has been found to moderate the attitude-intention relationship (Knussen and Yule, 2008). Ittiravivongs (2012) found that habit was reported the second largest factor in interviews in a study in Thailand.

The work reported here takes place in China, where there has been intense recent research and policy experimentation on residential recycling (Zhang et al., 2019; Fan et al., 2019; Meng et., 2019; Wang et al., 2019; Zhang and Xu, 2020; Bi, 2020),. Bi (2020) researched community participation, indicating lack of resident mobility as a challenge, alongside lack of awareness, knowledge, and insufficient engagement in policy formulation. Zhang and Xu (2020) used the theory of embedded social structure to show that perceptions of economic and ecological value of waste can influence recycling behaviour, as well as institutional trust, community participation, social norms and community characteristics. These studies usually used self-reported measures.

\subsection{Development of a Prescriptive Theory to fill a wide need}


A systematic review of the hundreds of published papers in major international waste journals since 1990 which report on determinants of residential recycling (not yet published), shows something remarkable: only 41 of those involved direct measures of the behaviour (as opposed to self-reported), and of those, none made use of any theories at all except two which retrospectively checked for consistency (Tonglet et al., 2004, Tucker et al., 2000). We found zero examples of recycling programs making use of theories associated with recycling behaviour, in their planning or design. There is thus a clear disconnect between theory and practice in residential recycling, and theory is not currently providing for practice-based needs. This state of affairs is reflected in the documentation $f$ the evolution of UK government strategies to make progress with recycling behaviour changes, which were not based on disciplinary theories (Eppel et al., 2013)

On the other hand, the practice of residential recycling is itself a complex activity taking place in complex environments strongly influenced by norms, institutions, governance, infrastructure, lifestyles, values and many other factors (Evans 2012; Evans, 2014; Jackson 2005; Varotto and Spagnolli, 2017; McCarty and Shrum, 1994). It is therefore not surprising that it is difficult to identify patterns of factors for generalised learning, starting from any single perspective. Each associated academic field builds theories with respect to its own disciplinary foundational framework of knowledge, sometimes extending to include a few concepts from other disciplines. However, for residential recycling, the progress from such a disciplinary-focussed approach towards an overreaching and pragmatic Prescriptive Theory is lamentably slow. In the meantime the consequences of urban waste in terms of greenhouse gas emissions, ground pollution, fossil fuel usage in incinerators, and marine pollution are becoming increasingly intolerable (Edenhofer, 2015). Governments around the world, and especially in China, are currently demonstrating a willingness to invest in resources, and infrastructure (Huang et al., 2014), but there is insufficient knowledge of how to obtain and maintain residential cooperation to sort waste at the household level. This is true for all types of residential recycling, but especially true for food-waste sorting (Woodard et al., 2001) which is the most challenging to sort, collect and process sustainably, and which most cities still do not even attempt to divert. There are many reports of pilots and trials, but only a handful of successes: a recent publication on a rare large-scale, long-term residential food waste sorting program in Nanjing (Li et al., 2017) only reported four previous programs - all short-term, lowyield and/or small-scale. There is thus a global need for better design of residential food waste recycling programs, but no clear guidelines emerging from practice or theory, and no 
idiosyncratic success stories that can be emulated (Eppel et al., 2013; Geislar, 2017).

\subsubsection{Finding a way to start Stage 1 theory building}

There are many sources of complications in field work with recycling that have greatly hampered systematic studies based in empiricism. Decisions to recycle are generally made at the household level, but households are usually serviced by a variety of different providers operating under different regulatory guidance and infrastructures, making clean investigations of determinants of behaviour extremely difficult. For example, vehicles collecting recyclates usually cover different areas of town and routes to those collecting residual waste, and pick up on different days and times. Thus, the direct measurement of changes in actual recycling performance are notoriously difficult to obtain, and even more difficult to link to any specific intervention (Harder et al., 2008).

Our research team has taken advantage of the fact that many cities in China arrange their standard residential housing in compounds with a surrounding wall, few gates, and common gardens, parking, governance and waste facilities. This has allowed us to systematically study residential compounds, and to slowly develop a theory in the style shown in Figure 1, by making use of contained circumstances to build up the Stage 1 typology of candidate attributes of phenomena. Our first five studies took place in a narrow range of circumstances, with broadly similar demographics and housing types, stakeholder involvement processes facilities and service types (Dai et al., 2015; Xu et al., 2016; Dai et al., 2016; Lin et al., 2016; Huang et al., 2018). They involved pilot recycling programs with varying levels of success which emphasised the use of volunteers for door-stepping and/or manning the communal recycling bins four hours a day to influence residents and model the actions for them. For this reason, we named these, broadly speaking, the Volunteer Circumstances. The early studies used a grounded approach with deep, multi-case studies for open explorations of determinants considered important with respect to the perspectives of several different stakeholders involved (Dai et al., 2015; Xu et al., 2016). Those grounded descriptions of phenomena often overlapped with or linked to the lay descriptions of the circumstances, such as 'door-stepping', or 'the actions of the volunteers', and these had to be deconstructed into more specific determinants through specialised studies (Lin et al., 2016; Huang et al., 2018). In Figure 1 this can be understood as linking Transitions between Stages 1 and 2, where iterations are needed to hone in on what categorisation systems for the phenomena, and for the circumstances, were useful. In this way, for 
example, the phenomenon of 'actions of the volunteers' was eventually deconstructed into aspects such as: interpersonal interaction, social influences, tacit modelling of the behaviour, emotions like respect, and prompting effects (Xu et al., 2016; Lin et al., 2016). Other candidate-determinants which emerged from the five studies included: procedural knowledge (Dai et al., 2016); tailoring of information (Huang et al., 2018); belief of capability (Xu et al., 2016); role clarification (Xu et al., 2016); and belief of (environmental) consequences (Dai et al., 2015). Many of these resonated with constructs used in sociopsychological models such as social influences (Abrahamse et al., 2013), but the details were often different. For example, the correlation of better recycling performance with the use of volunteers was linked to reported 'social influences' (Xu et al., 2016), but when we performed an experiment controlling for all six social influence types reported in the sociopsychological review of Abrahamse et al. (2005), we found none of those accounted for the effect we measured (Huang et al., 2018). Rather, our study pointed to 'positive interpersonal interactions' as being an important determinant of better recycling performance (Huang et al., 2018) even when the volunteers were not known locally, communicating judgemental opinions, or part of social networks.

Taken together, the 'attributes of measurable phenomena' identified in the early studies provided us with a draft typology: they are candidate-determinants in one (broad) type of circumstance, correlated to improved performance. (Typologies generally do not include understandings of causality, or relationships between determinants). This meant that the theory building could move deeper into Stage 2 as indicated by the triangle on the right in Figure 1, where the desired outcome (improved recycling performance) is iteratively examined in different circumstances and thus for tests of causality. However, this clearly required studies in significantly different circumstances.

\subsection{Moving the focus to Stage 2 theory building}

Moving to Stage 2 for causal testing of determinants in new circumstances required us to first find and set up a field area involving new circumstances. A case study was thus set up as our sixth study, to establish the main candidate determinants in a successful recycling program in Nanjing which centred on giving financial incentives to participants. We named this the Incentives Circumstance, broadly speaking. Residents received Green Points on household smart-cards which could be exchanged for common items like eggs and tissues. We used a grounded approach to inductively identify the main determinants correlated with 
improved recycling performance, with the expectation that many of them would overlap with the first, Volunteers Circumstance (Li et al., 2017). Exploratory interviews suggested that residents were initially motivated by the determinants of incentives and some social influences (their "neighbours were doing it"), but that habit of the targeted behaviour was the key factor for maintaining their behaviour after 22 months, and also the main reason they would continue if the incentives stopped (Li et al., 2017).

When comparing the candidate determinants which emerged from the Incentives Circumstances compared to the Volunteers Circumstances, several points stood out. First, the strong references to habit could be retrospectively found as existing, but weak comments which analysers had not coded for in the Volunteers Circumstances studies, providing some cross-study linking. However, the strong determinant of 'interpersonal interaction', known from the Volunteers Circumstances did not emerge at all in Incentives Circumstances, which seemed an inconsistency. There are substantial 1-2-1 interpersonal interactions going on between participants and the staff dispensing the Green Points, which would be expected to be generating an effect, if that determinant was important across both Circumstances.

It was thus decided to design our seventh study, which is the one reported here, as a Stage 2 focussed experiment of the relative causal contributions to the measured recycling performance, of the established determinants of Incentives, Habit, and 1-2-1 Interpersonal Interaction - while being aware that other factors might also be competing. Our prediction, taking into account all six previous studies, was that all three of these would be significant, that habit would grow and interpersonal interaction decrease as time went on, and that there will not be any other determinant of the same magnitude. With this in mind, we designed an experiment to test the causal relative influences of these three candidatedeterminants on directly measured recycling performance, across communities with ongoing programs of different time spans.

\section{Methodology}

The purpose of this investigation is to develop our prescriptive, empirically-based middlerange theory building of residential recycling by testing our current typology of determinants under new circumstances: where Incentives are used. Three candidate-determinants would be tested for causal links to measured performance with the following methodology. For two 
weeks, residents would receive their personal incentives (Green Points) without any requirements to deposit sorted food waste. In other words, the incentives will be decoupled from deposits of sorted food waste, without any loss to the residents. They would be told about this temporary change clearly, and in advance. We predicted, from exploratory work in Incentives Circumstances (Li et al., 2017), that the determinants of Incentives and Habit are both contributing, and this intervention should reveal the relative contributions of each via the direct measure of participation rates before, during and after the decoupling. As a check, the tonnages of sorted food waste deposited for recycling would also be measured in each period, and a small number of interviews of residents would be taken for triangulation.

However, we also predict, from our typology emerging from all six previous studies including in Volunteers Circumstances, that evidence could be revealed of a characteristic that is underrated and somewhat hidden: 1-2-1 Interpersonal Interaction between participants and the regular Green Points staff members (and possibly other participants). Pragmatically, the strength of this determinant is important to understand, because Interpersonal Interactions are expensive to provide commercially, but might be possible to plan for using organised volunteers or peer groups to replace them.

To test this, we planned to remove the staff members, not for all of the two weeks of 'free incentives' - but instead have them 'unexpectedly' return a few days early to perform incidental tasks (not giving out points), to see how many residents change their behaviour in response. (Technically, there could be other 'social influences' acting, such as residents being concerned to be seen by others - but we could not design this particular experiment to be more precise - a limitation to mitigate in future specialised studies.) Residents turning up to the deposit site too early would be reminded that the period of decoupled incentives has not yet finished: no scanning of smart cards or indeed actual deposits was yet required to receive the points. A schematic summary of the experimental, pre- and post- conditions is shown in Figure 2.

To compliment the quantitative data of participation rates and recycling tonnages, a small number of in-depth interviews were planned in each community for 3-5 residents during the experiment period to check on their understanding and perceptions of the experimental conditions, and 20+ post-experiment interviews of residents to explore how they framed their actions during and soon after the decoupling period. Ethical approval was sought and 
waived from the university committee, which prioritises medical research.

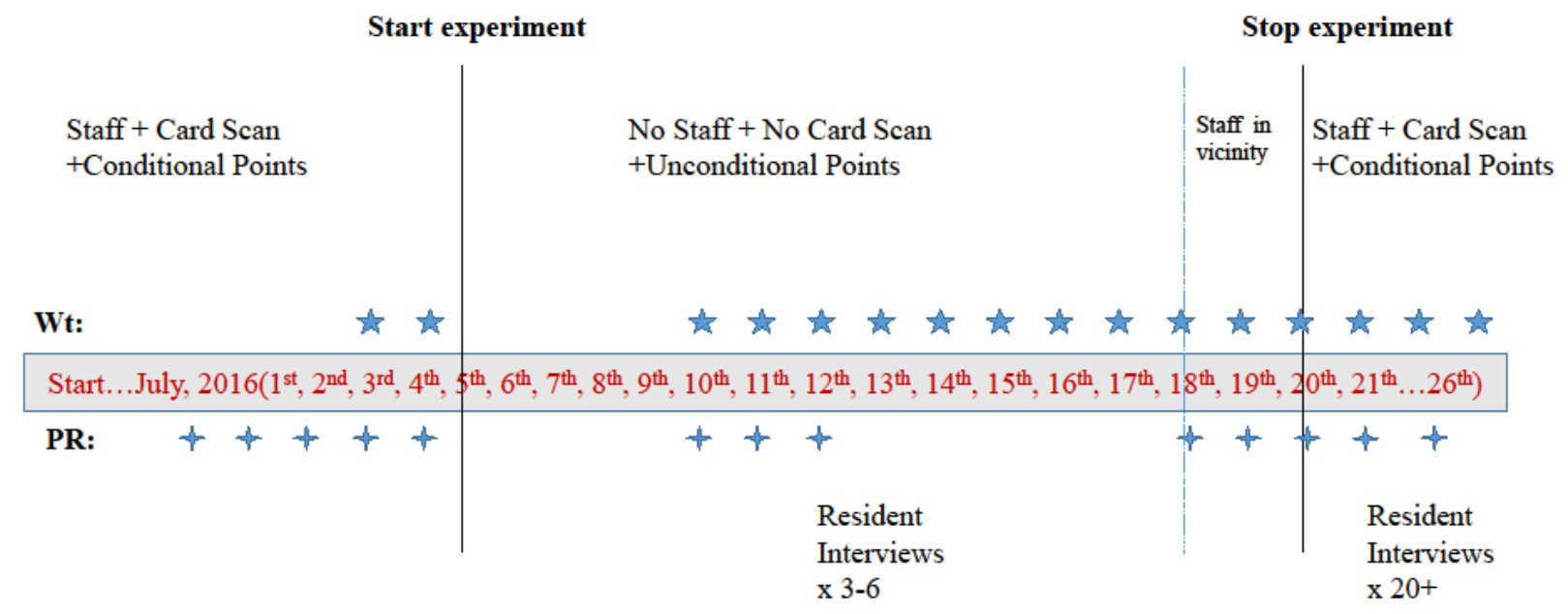

Figure 2. A timeline of the pre-, post-, and during-experiment activities and conditions. (Seven control communities would had parallel measurements but no experimental conditions. $\mathrm{PR}=$ participation rates. $\mathrm{Wt}=$ tonnages of food waste sorted into correct bins by end of day.)

\subsection{Site selections}

This work was done in collaboration with the government-appointed company which managed the recycling program in Nanjing. In 2013 the Nanjing Municipal Government launched a national demonstration program known as the Nanjing Green Account scheme, in which residents gain electronic points if they sort their food waste into designated containers. City wards entered into a Public-Private Partnership, at roughly 20 RMB (\$2) per household per year. They initially dealt with twenty-three communities (twenty thousand households), with 6000 households voluntarily participating. The case sites were selected from those communities, where the long-term data on participation rates, and daily tonnages, did not have any anomalies e.g. due to technical or staff issues (see map in Figure 3). As one of the determinants under investigation, Habit, would be expected to vary 
depending on how long the program had been established in a given community, it was decided to include a range of periods. Since the company reported that it can take 4-6 months for the behaviour effects of a program to stabilise, the selection criterion was $6+$ months, and the maximum available was 23 months. Communities are often categorised as either 'Dismantling and Settling' (D\&S: where communities who lived together elsewhere had been re-settled as part of an urbanisation plan), or 'Commercial \& Residential' (C\&R: where commercial properties were mixed with residential which were available to tenants with no regard for their prior settlement). Our ongoing series of research has not shown any obvious correlation of the type of community with recycling performance, but we note it for reference, and include both types. Furthermore, the company reported that anomalous circumstances sometimes occurred in very small or large communities, $(<200$ or $>2000$ households), so these were avoided, and the researchers de-selected those with very high or very low levels of participation because it is established in the literature that very lowand high- performers can respond differently to interventions (Cox 2004; Harder and Woodard 2007). Finally, communities which belonged to the same 'wards', with similar demographics and local governance, were paired and randomly assigned to control or experimental conditions (Table 1,2).
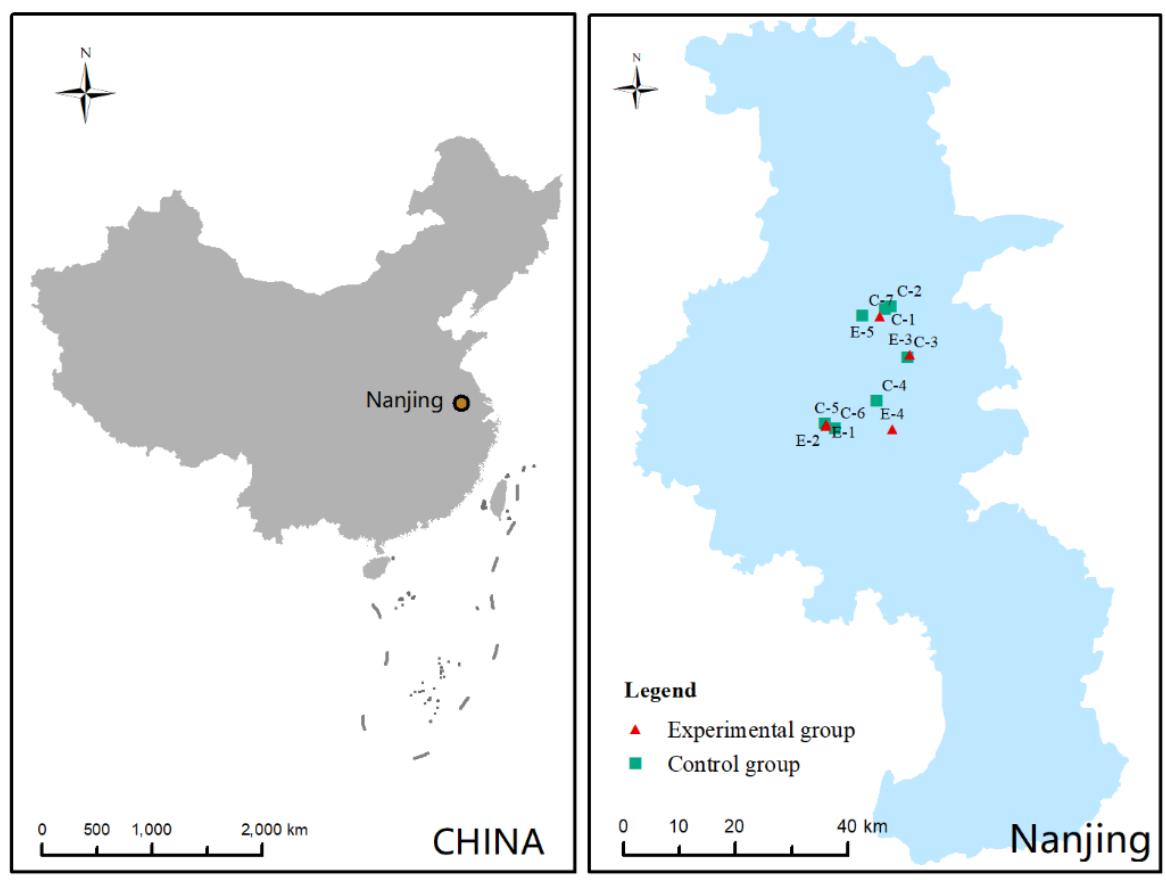

Figure 3. Map showing the sites of the work 
Table 1 Characteristics of the experiment communities.

\begin{tabular}{ccccccc}
\hline Experiment & Type & $\begin{array}{c}\text { Building } \\
\text { type }\end{array}$ & $\begin{array}{c}\text { Total } \\
\text { Household } \\
\mathrm{s}\end{array}$ & $\begin{array}{c}\mathrm{PR}_{\mathrm{m}} \\
(\%)\end{array}$ & $\begin{array}{c}\text { Continue } \\
\text { months }\end{array}$ & Location \\
\hline $\mathrm{E}-1$ & $\mathrm{D \& S^{ \textrm {a } }}$ & $6 \mathrm{~F}^{\mathrm{c}}$ & 1616 & 35 & 14 & downtown \\
$\mathrm{E}-2$ & $\mathrm{D} \& \mathrm{~S}^{\mathrm{a}}$ & $6 \mathrm{~F}^{\mathrm{c}}$ & 1532 & 32 & 23 & downtown \\
$\mathrm{E}-3$ & $\mathrm{D} \& \mathrm{~S}^{\mathrm{a}}$ & $6 \mathrm{~F}$ & 1268 & 23 & 11 & suburb \\
$\mathrm{E}-4$ & $\mathrm{C} \& \mathrm{R}^{\mathrm{b}}$ & $11 \mathrm{~F}^{\mathrm{d}}$ & 405 & 39 & 10 & downtown \\
$\mathrm{E}-5$ & $\mathrm{C} \& \mathrm{R}^{\mathrm{b}}$ & $6 \mathrm{~F}^{\mathrm{c}}$ & 500 & 19 & 15 & suburb \\
\hline
\end{tabular}

${ }^{a}$ D\&S: Dismantling and Settling building

${ }^{b}$ C\&R: Commercial Residential building

c $6 \mathrm{~F}$ : Six floors or seven floors

$\mathrm{d}_{11 \mathrm{~F}}$ : Eleven floors or twelve floors

$\mathrm{PR}_{\mathrm{m}}$ at June, 2016

Price: Website: http://www.fang.com/ at August, 2016

Table 2 Characteristics of paired control communities.

\begin{tabular}{|c|c|c|c|c|c|c|}
\hline $\begin{array}{l}\text { Control } \\
\text { Community }\end{array}$ & Type & $\begin{array}{l}\text { Building } \\
\text { Type }\end{array}$ & $\begin{array}{c}\text { Total } \\
\text { Households }\end{array}$ & $\begin{array}{l}\mathrm{PR}_{\mathrm{m}} \\
(\%)\end{array}$ & $\begin{array}{l}\text { Continue } \\
\text { Months }\end{array}$ & $\begin{array}{c}\text { Paired } \\
\text { Experiment } \\
\text { Communities }\end{array}$ \\
\hline $\mathrm{C}-1$ & $C \& R^{b}$ & $6 \mathrm{~F}^{\mathrm{c}}$ & 1231 & 26 & 23 & E-5 \\
\hline C-2 & $\mathrm{D} \& \mathrm{~S}^{\mathrm{a}}$ & $6 F^{c}$ & 1182 & 25 & 23 & $E-5$ \\
\hline $\mathrm{C}-7$ & $\mathrm{D} \& \mathrm{~S}^{\mathrm{a}}$ & $6 F^{c}$ & 1231 & 40 & 14 & $E-5$ \\
\hline C-3 & $\mathrm{D} \& \mathrm{~S}^{\mathrm{a}}$ & $6 F^{c}$ & 2485 & 20 & 11 & $E-3$ \\
\hline C-4 & $C \& R^{b}$ & $11 \mathrm{~F}^{\mathrm{d}}$ & 312 & 34 & 17 & $E-4$ \\
\hline C-5 & $D \& S^{a}$ & $6 \mathrm{~F}^{\mathrm{c}}$ & 540 & 38 & 12 & $E-1 \& E-2$ \\
\hline C-6 & $\mathrm{D} \& \mathrm{~S}^{\mathrm{a}}$ & $6 F^{c}$ & 980 & 39 & 11 & $E-1 \& E-2$ \\
\hline
\end{tabular}

a D\&S: Dismantling and Settling building

${ }^{b}$ C\&R: Commercial Residential building

c $6 \mathrm{~F}$ : Six floors or seven floors

d11F: Eleven floors or twelve floors

$\mathrm{PR}_{\mathrm{m}}$ at June, 2016

Price: Website: http://www.fang.com/ at August, 2016 


\subsection{Quantitative measures of recycling performance}

\subsubsection{Pre- and Post-Experimental period measures}

The recycling program established in all the communities used for this study already have in place a 'smart-card' system whereby each household is registered to one card, which is presented to a company staff member on duty from 7-9 a.m. each day at a central location in the campus of the residential compound, where communal bins are set out for food waste and residual waste. This arrangement is different to many other cities in China where bins are still commonly placed on each floor of each building - but it is quickly becoming the new norm. There are also nearby communal bins for hazardous wastes and 'dry recyclables' such as plastic bottles and glass jars. As residents arrive, their cards are scanned by a company machine, and receive 'Green Points' at a maximum of one per day for depositing the sorted food waste into the allocated communal bin. The company thus has precise data on the history of deposits of all households. The total number of those participating on a given day, divided by the total number of households in the compound, gives that community's daily Participation Rate, PR:

$P R=\frac{\text { Number of households Participating }}{\text { Total number of households in the community }} \times 100$

Pre- and post- experimental period, these data would be routinely collected by company staff.

Additionally, as a check for possible unexpected effects, the actual weights of the diverted food waste deposited in the bins was recorded at the end of each 24-hour day on most days of interest, shown by stars in Figure 2.

\subsubsection{Experimental Period Measures}

Direct measures via scanners could not be made during the Experiment period, since residents had been told, (for the seven preceding days), that there would be no staff present between July 5-20 2016 inclusive as "they would be needed for training at other sites and for other tasks", and for that reason residents would receive 'free' Green Points regardless of whether they made food waste deposits or not.

Another method was thus needed to monitor the numbers participating, and this was done by company staff through the use of visual observations and discreetly counting the number of participants depositing each day during the usual period 7-9 a.m., from some distance 
away, while carrying out unrelated duties.

\subsection{Qualitative data collection during and after the experimental period}

The research design specifically included two checks as opportunities to see if any unexpected determinants were perceived by participants to influence their response to the 'free' Green Points. Both involved (convenience sampling) interviews with residents and open questions about how they 'felt' about recycling while there were no staff there. Only a very small number (3-6) were interviewed during the experiment period, in order to minimise any chances of influencing participant behaviour. They were considered necessary as a triangulation check on the post- interviews, because sometimes people shift their views when asked retrospectively. A larger number (between 15-45 in each community) were interviewed post-experiment. The questions asked were purposely open:

"There is/was no staff and no scanning of cards recently/ for the last two weeks. Did you continue to deposit food waste or not?... Any particular reason?"

For comparison, we also then asked residents which reasons they recalled for starting their food waste sorting practice:

"We are interested to know what the reasons are, that people start recycling their food waste in the first place (at the start of the program). Can you tell me why you started, at the beginning?"

The answers were open-coded thematically using terms as close as possible to those in the text, with a second round of coding across all interviews with the final set of grounded codes. Two researchers coded independently and then discussed results: they obtained no differences.

\section{Results and Data Analysis}

The experiment was designed to be relatively simple: to reveal participation rates dropping due to the rational actors whose habit was weaker than their interest in the incentives (Figure 4a) against the controls (Figure 5). However, the second set of measures, of the daily weight of recycling (Figure $4 b$ ), revealed an unexpected new determinant, and much more rich results, once the two were normalised. These are laid out below. 

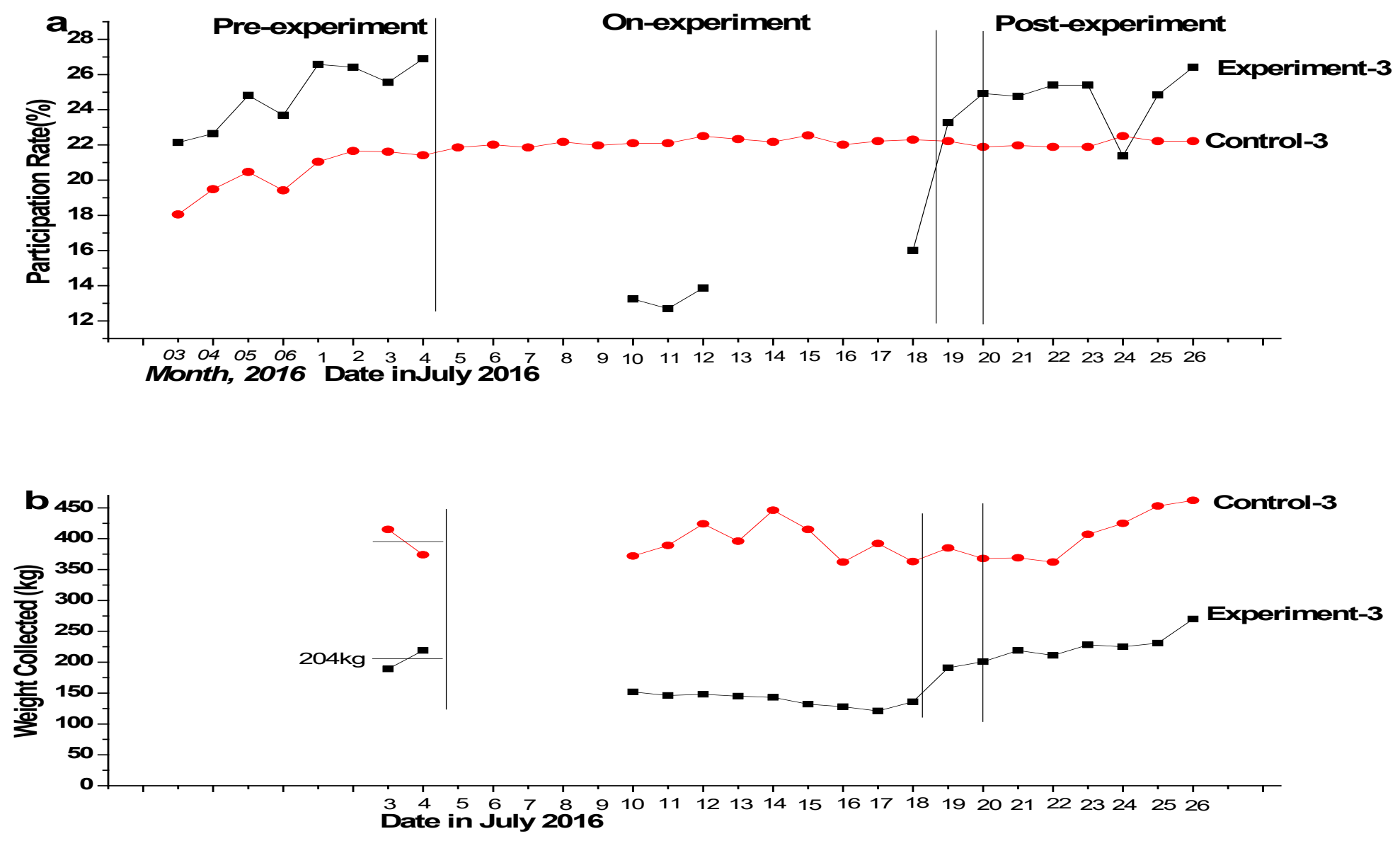

Figure 4. Direct measures of recycling performance Pre-, On-, and Post- Experiment, Community \#3 and Control Community \#3. (The Pre+Post measures of weights (food waste deposited for recycling) were normalised to the PR measures shown, to obtain the number of 'Inconvenienced' in Figure 5.) 


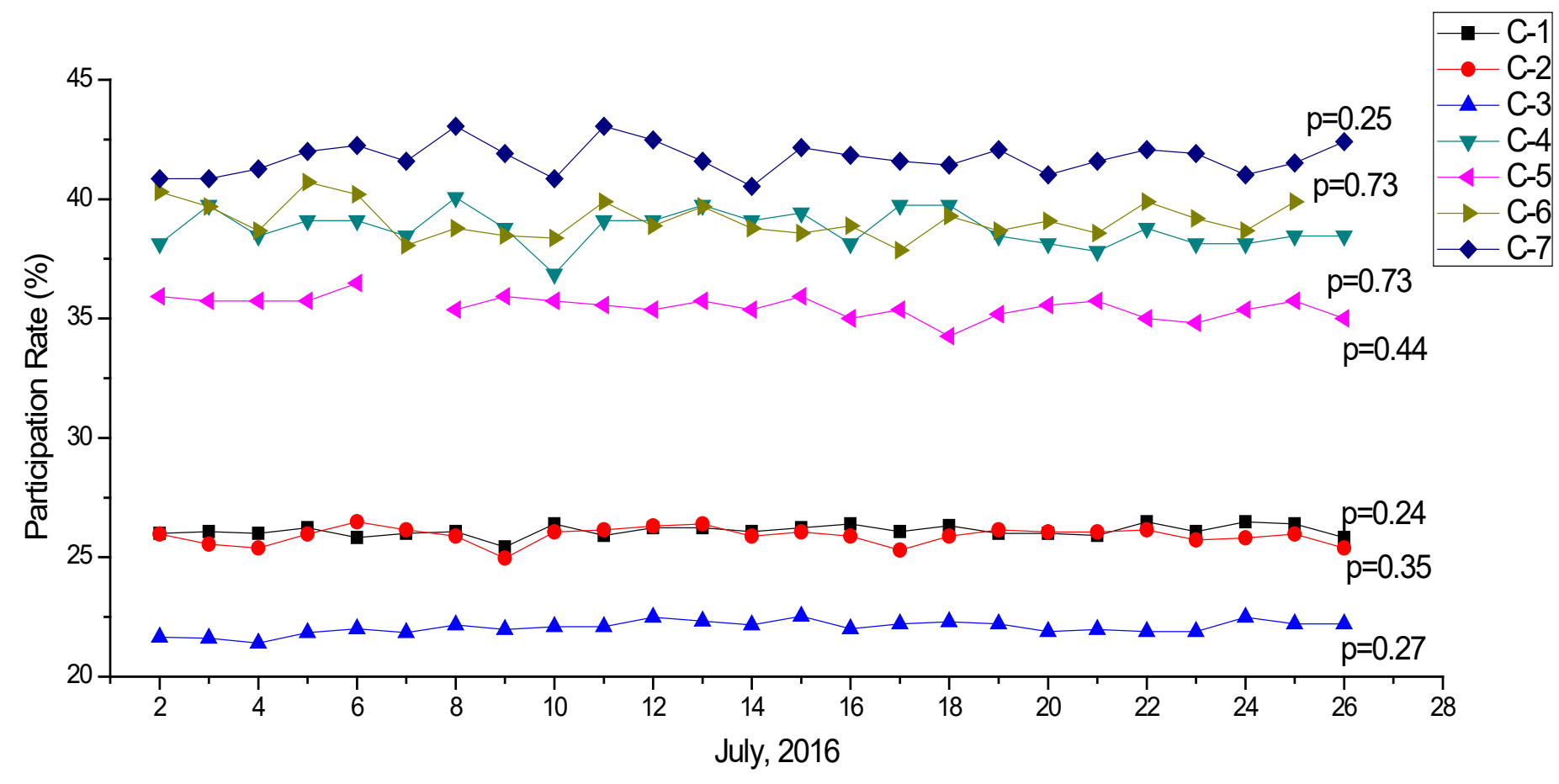

Figure 5. Direct measures of direct recycling performance Pre-, On-, and Post- Experiment) for Control Communities \#1-7. (Note their steady state compared to the Experiment Communities.) 
(1). The tonnages of food waste collected in each 24 -hour period reduced only by $20 \%$ $25 \%$ when incentives were uncoupled to behaviour (Figure 4b). The label ' $G$ ' in Figure 6 indicates the corresponding numbers of participants who 'G: Gave up'.

(2). The participation rates within the normal 2 hours (7-9 a.m.) reduced by $50 \%-55 \%$ during the experimental period (Figure 4a). Those who continued to participate are represented by the label ' $D$ : Determined' in Figure 6.

(3). The difference between the numbers in 1 . and 2. above indicate that $25 \%-30 \%$ of the participants continued to sort and deposit their waste - BUT NOT within 7-9 a.m. This suggests that other times of the day were more convenient to them. This is illustrated in Figure 6 with the label 'I: Inconvenienced'. It was calculated by first normalising the data on weights and PRs to each other, and then finding the difference.

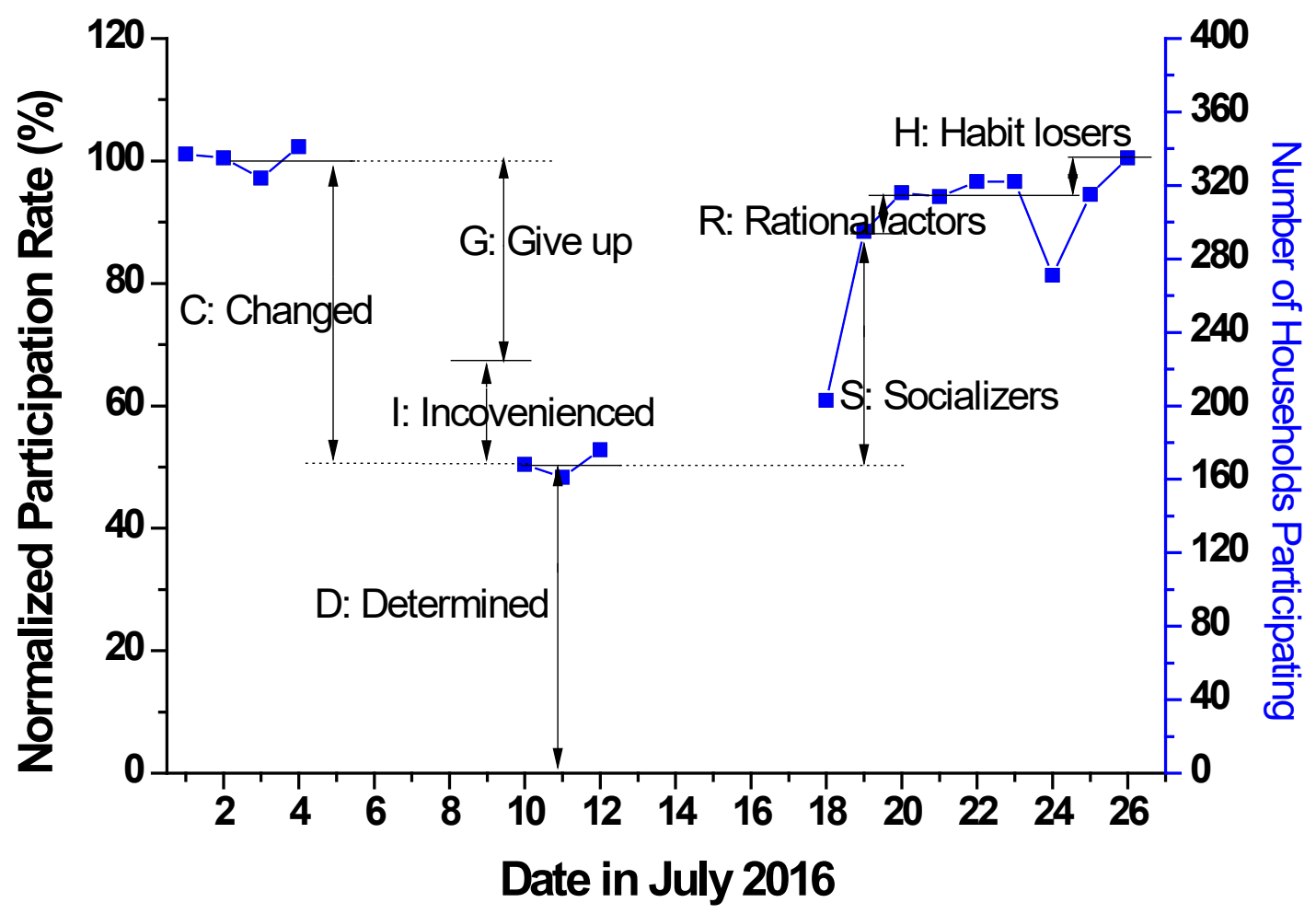

Figure 6. A breakdown of the changes in Participation Rates by behaviour type. ('C' participants changed their behaviour in some way, comprising 'G's who gave up participating and l's who continued but at a different time of day. The ' $S$ ': Socialisers returned early when staff were seen, but ' $R$ ' participants only turned up when the deposits in 7-9 a.m. were strictly required for Green Points. The Habit Losers took 
some time to reinstate their previous behaviour. The number of 'Inconvenienced' was determined by normalising the Pre+Post weight measures with the PR measures.)

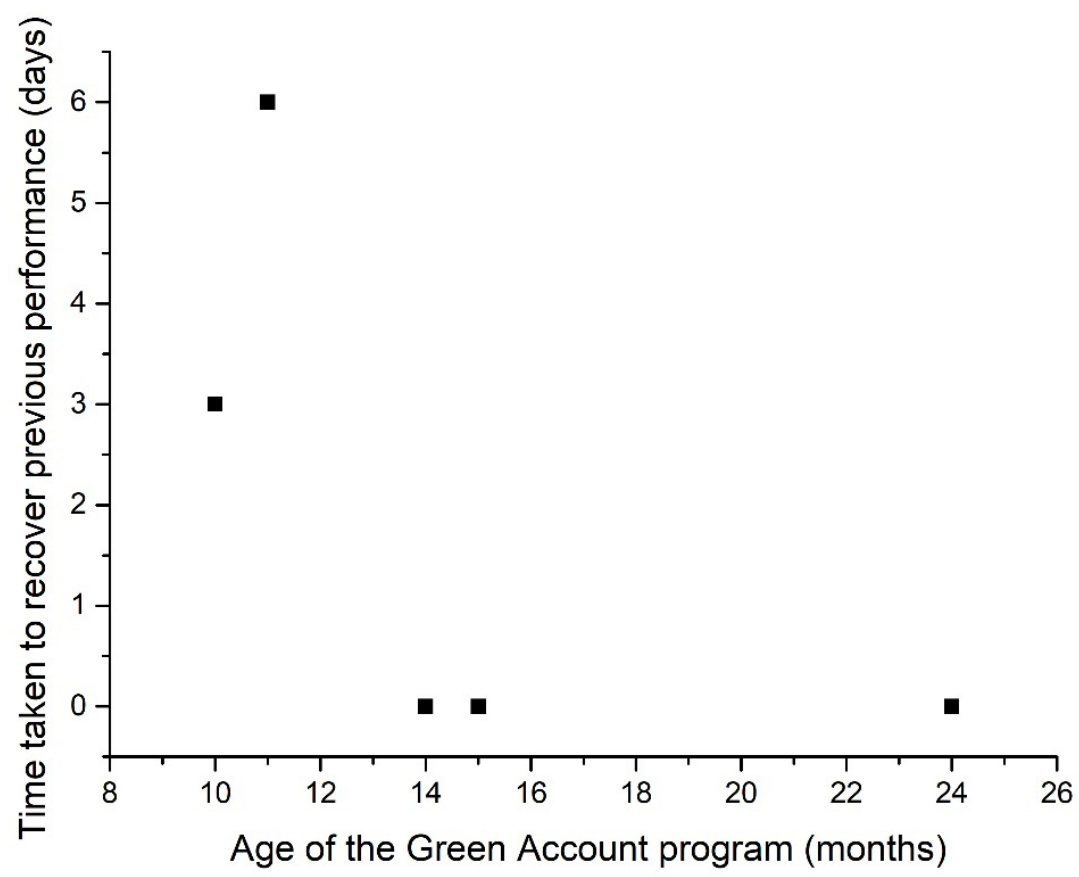

Figure 7. The number of days before participation rates recovered fully. (Counted after the end of the experiment, i.e. after incentives and behaviour were again coupled on July $20^{\text {th }}, 2016$. Shown with variation with the number of months that the Green Account program had been established in each community.)

(4). The number of residents depositing waste within the 7-9 a.m. slot increased greatly when the staff members returned two days early (July 18,19) - even though the incentives were still uncoupled to the deposits (and residents were explicitly reminded of this). This suggests that some kind of social influence was involved, e.g. a desire to interact with the staff member, or with other participants, or 'to be seen participating'. These participants were labelled 'S: Socializers' in Figure 6. The number of them was unexpected and relatively large, ranging from 10-35\% across the Experiment Communities \#1-5.

(5). The number of participants that only resumed after deposits were required again to get the points, was found to be quite low. That number could be identified in two parts: as the additional number that turned up compared to the previous day, labelled ' $R$ : Rational 
Actors' (i.e. desiring a benefit for the effort of turning up) in Figure 6. And those who did not resume for several days, suggesting they were 'H: Habit-losers', (but not conclusively Rational Actors also, as they may have been highly inconvenienced instead/also). Interestingly, the number of days taken for the participation rates to return to preexperiment levels varied, in line with the number of months that the program had been established, as shown in Figure 7.

\section{Discussion}

The main objective of this study was to test three determinants for their relative causal contributions to recycling performance: Incentives, Habit, and one-to-one Interpersonal Interaction. They had been identified in our Stage 1 theory-building work, in the non-causal typology. We wished to establish their relative influence in the specific circumstances. At the same time, we designed the study with data checks and qualitative interviews to allow some possibility of unexpected determinants showing. The results were much richer than expected.

\subsection{Determined participants: $80 \%$-ish}

Firstly, it was possible to obtain a measure of the number of participants who $G=$ Gave Up depositing entirely (see Figure 8), and those who deposited at other times due to likely $\mathrm{I}=$ Inconvenience, and those who continued 7-9 a.m. in a D=Determined manner. (This was done by normalising the Pre+Post weight measures with the PR measures.) Figure 8 shows these results, including the variation depending on how long (months) the program had been established in each community. Those established more than 12 months show similar patterns, with smaller Give-Up numbers and more Determined than those established less than 12 months. In fact, around $80 \%$ of those already participating pre-experiment continued to do so - a very useful result to know for cities who start up incentives schemes in the hope that they can be tapered off once participants have developed a firm habit. The data suggests that after about 12 months a firm habit is established. We had not expected to show such a result, but it is in line with previous studies (Knussen and Yule, 2008; Ittiravivongs, 2012). In particular, Ittiravivongs (2012) researched the influence of habit on household waste recycling behaviour in Thailand with personal interviews, and found it to be his second largest factor, after recycling intention. 


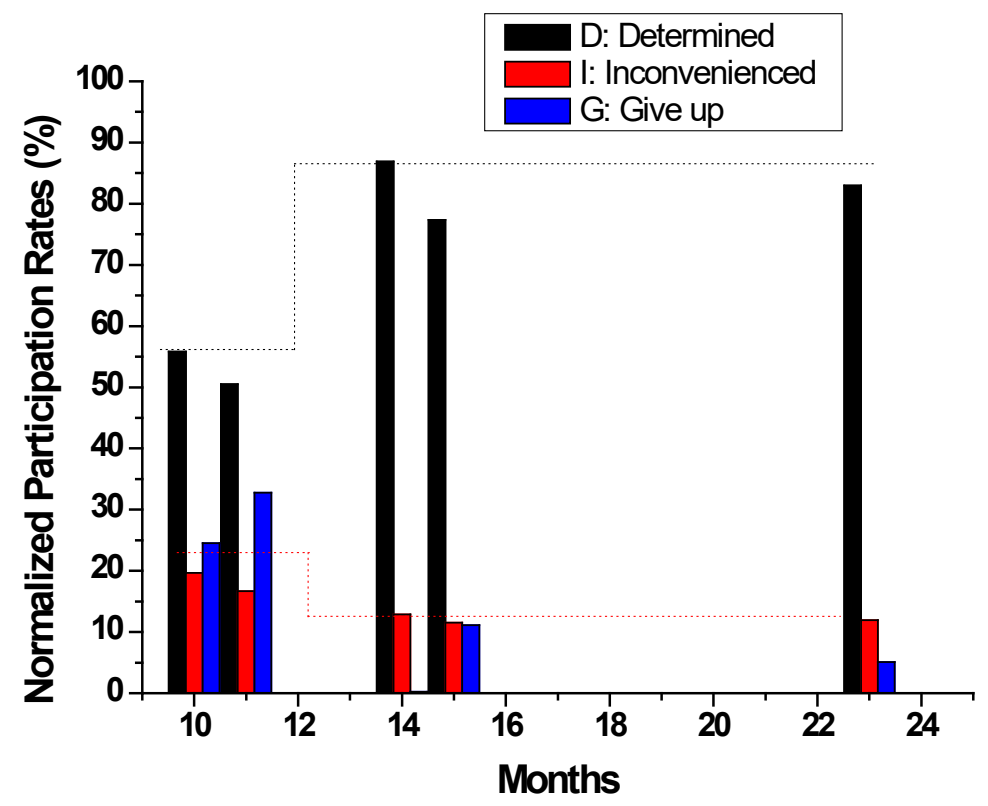

Figure 8. The normalised Participation Rates corresponding to Determined, Inconvenienced, and Give-Up participants (normalised to the Pre-experiment levels). (The 'Inconvenienced' also deposited food waste (See Figure 6), but not within 7-9 a.m. Programs established more than 12 months show smaller Give-Up numbers and more Determined than those established less than 12 months.)

\subsection{Inconvenienced participants:10-20\%-ish}

The research design had not expected to capture evidence of 'inconvenience' of the time slot, and indeed the evidence here is circumstantial: specially-designed post-interviews would have been very useful here: unfortunately, our interview questions were not designed to explicitly reveal time-inconvenience, and neither have our previous studies. Because waste sorting is a complex behaviour with many facets, a more full study of the lifestylerelated practice of it (e.g. Evans 2014) would be very useful to clarify exactly which aspects caused this measured effect - that residents preferred to deposit waste in different hours. What is very noteworthy here, is the size of the effect: up to $20 \%$ showed signs of timeinconvenience in the less-established programs ( $<12$ months), which was still at $10 \%$ for the very established ones. The program planners currently do not take time-inconvenience into account: we have not heard any discussions about optimising the time-window when Green Points are given out, or extending it. Thus, this data is a useful indicator to the program practitioners that they should reconsider the importance of this factor. 
Furthermore, the size of it is worrying in that it suggests that this may indicative of a bigger issue for the non-participants: those $55 \%+$ who have not been participating at all. From a theoretical point of view, these results should be of interest to pro-environmental behaviourists to see that, in these circumstances, half of those showing inconvenience in the first year of a program may modify their lifestyles such that the behaviour is not seen as inconvenient after that. The data suggests these ideas are worth further investigation.

\section{3 Habit: $>80 \%$}

The data revealed the correlations of Habit with recycling performance, as intended in the research design. Figure 7 showed that the 'R'=Rational Actor participants and even the ' $H$ '= Habit-losers 'snapped' straight back into Pre-Experimental performance levels as soon as the situation returned to normal, for communities where the program had been established more than 12 months. This correlation is supported by the data in Figure 9, where the number of $\mathrm{R}$ participants is shown to reduce by roughly half - and the number of $\mathrm{H}$ participants is near-zero - for programs established more than 12 months. These results are very useful: as per Section 5.1 they suggest that city planners might be able to remove the 'incentives' part of incentives programs if habit has been firmly established, e.g. after 12 or perhaps 18 months. This is a very important result both financially and logistically, because they suggest in principle that such an incentive scheme might help initially establish the desired habit but then have its costs greatly reduced 12-18 months later. We caution that different circumstances could vary this effect, and the most critical factors are not yet explicitly identified (see Section 5.4).

\subsection{Social Influences - the largest of all!}

The research design was centred on the concept that the 1-2-1 interpersonal interaction of the company staff might have been important (due to separate studies in the Stage 1 theory building of the typology). The fact that so many of the participants in the experiments returned when the staff returned - even on the very same day and thus within 1-2 hours of their first appearance - suggests there is a very significant social influence of some kind at play (see Figs $5,7,8$ ). In fact, Figure 9 shows the scale of this influence to be more than triple that of the 'Rational Actors + Habit-losers', who only returned when necessary to earn the points, from July $20^{\text {th }}$ onwards. 


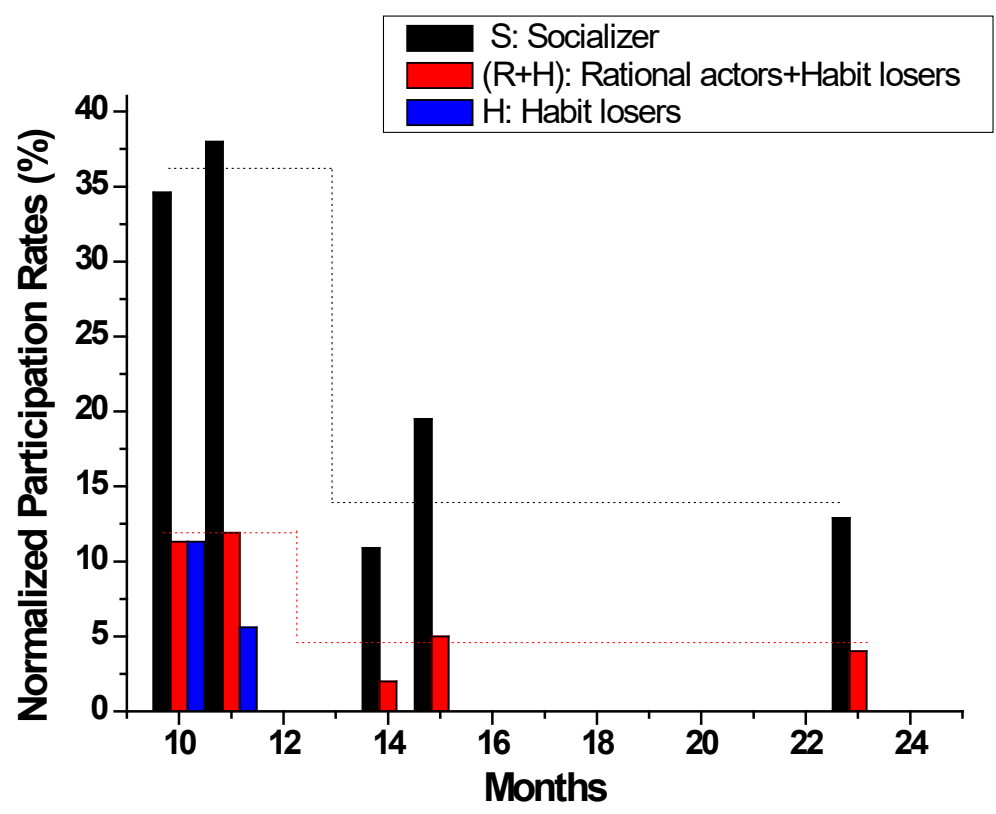

Figure 9. The normalized participation rates of different types of participants. (Shown with respect to the number of months the 'incentives' program was established. The $\mathrm{R}=$ Rational Actors only returned when necessary, and Habit Losers returned a few days later. $\mathrm{S}=$ Socialisers returned two days before necessary - when the staff returned, unscheduled. The types are non-discriminatory, and defined in Figure 6.)

However, it was understood in advance that the research design of the experiment part would not able to distinguish between different possible sources of social influence, such as the presence of the staff (who were regular), the presence of other participants, and in both cases whether due to interpersonal interactions themselves, or concerns of judgement, or indeed for internalized norms such as morals, triggered by an interpersonal interaction. Rather, it was hoped that the open questions in the post-interviews would provide grounded, qualitative indications of the nature of any social influences, which they did to a limited extent. They are summarised in Table 3, and discussed below.

Bearing in mind the completely open nature of the questions asked, it was reassuring to see 13 responses which explicitly referred to an interpersonal interaction of some kind always with the staff or the volunteers of the program. This means that this candidatedeterminant from the Stage 1 typology as proposed from the first, Volunteers Circumstance, is confirmed in the second, Incentives Circumstance. As in earlier studies, the respect, or 'Xinku' Chinese term for acknowledgement of effort, is explicitly mentioned.

At first glance it seems there are very few (4), other comments about norms. However, it is 
Table 3. The reasons given by residents (convenience samples totalling 173) for continuing to sort and deposit their food waste. (For two weeks even when the Green Points were 'free' and there were no staff or scanners at the deposit areas. Note this data is intentionally qualitative, and thus non-representative.)

\begin{tabular}{|c|c|c|c|c|c|c|c|c|c|}
\hline & \multicolumn{8}{|c|}{ Community } & \multirow{4}{*}{ Typical quotation } \\
\hline & \multirow{3}{*}{$\begin{array}{l}\text { Totals } \\
(132)\end{array}$} & \multirow{3}{*}{$\begin{array}{l}\text { Sub- } \\
t \\
(132)\end{array}$} & \multirow{3}{*}{ Reason } & E1 & E2 & E3 & E4 & E5 & \\
\hline & & & & \multicolumn{5}{|c|}{$\begin{array}{l}\text { \#(responses in each } \\
\text { community) }\end{array}$} & \\
\hline & & & & (16) & (32) & (45) & (21) & (18) & \\
\hline INCENTIVES & 2 & 2 & $\begin{array}{l}\text { Incentives (getting } \\
\text { points) }\end{array}$ & & & 1 & & 1 & $\begin{array}{l}\text { "...it is good to have the points...that makes } \\
\text { things more efficient..." }\end{array}$ \\
\hline HABIT & 35 & 35 & Habit & 6 & 7 & 10 & 7 & 5 & "This is my habit now so I do It anyway..." \\
\hline FUTURE & 1 & 1 & $\begin{array}{l}\text { For the next } \\
\text { generation }\end{array}$ & 1 & & & & & $\begin{array}{l}\text { "...waste sorting is for the good of our next } \\
\text { generation...We need to educate them on } \\
\text { this..." }\end{array}$ \\
\hline $\begin{array}{l}\text { PERSONAL } \\
\text { BENEFIT }\end{array}$ & 14 & 3 & $\begin{array}{l}\text { Personal benefit } \\
\text { (general) }\end{array}$ & & & 1 & 2 & & $\begin{array}{l}\text { "...I continued because now I can feel that I } \\
\text { actually benefit from it..."; "...waste sorting is } \\
\text { good for us (household)..." }\end{array}$ \\
\hline & & 5 & $\begin{array}{l}\text { Personal benefit (it } \\
\text { gives me something } \\
\text { to do) }\end{array}$ & & 1 & 2 & & 2 & $\begin{array}{l}\text { "I can also exercise on the way to drop the } \\
\text { waste...";"I have plenty of time so why not..." ; }\end{array}$ \\
\hline & & 6 & $\begin{array}{l}\text { Cleanliness/sanitation } \\
\text { of my household }\end{array}$ & & 4 & & 2 & & $\begin{array}{l}\text { "...No more mosquitos in my apartment after } \\
\text { sorting so it helps keep the sanitation insides..." }\end{array}$ \\
\hline $\begin{array}{l}\text { ENVIRON- } \\
\text { MENTAL } \\
\text { PROTECT- } \\
\text { ION }\end{array}$ & 32 & 32 & $\begin{array}{l}\text { A scientific way of } \\
\text { protecting the } \\
\text { environment (as per } \\
\text { government) }\end{array}$ & 6 & 15 & 3 & 3 & 5 & $\begin{array}{l}\text { "...because it is a scientific way to protect our } \\
\text { environment..."; "...waste sorting will prevent } \\
\text { environment pollution..." }\end{array}$ \\
\hline NORMS & 4 & 2 & Lots of people do it & 1 & & & 1 & & "We are doing this together and I just followed." \\
\hline
\end{tabular}




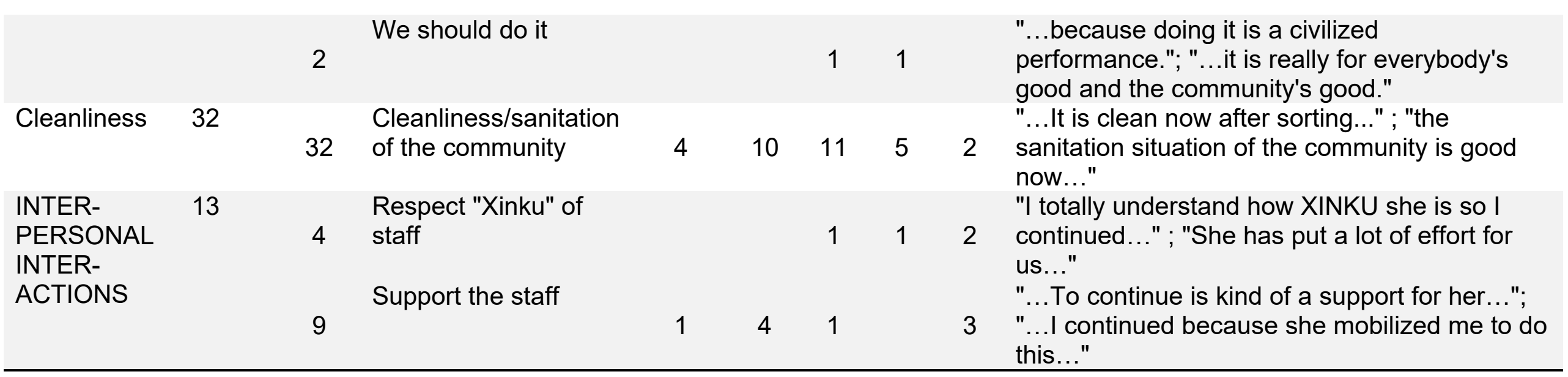


noteworthy that there are many, (32), for 'A scientific way of protecting the environment (as per government)', which is an interesting category which is not easily categorised by traditional boundaries. The native-language interviews show the use of language which reflects government slogans, implying residents have been made aware of a new priority, in which they have a role, which somehow involves environmental protection, and it is science-based (thus not purely ideological). The largeness of this response suggests it is important, and thus future research should be designed to investigate it more fully, both in terms of its pragmatic relevance for our Prescriptive Theory, and potential contributions in disciplinary theories in socio-psychology.

Lastly, Table 3 shows a large number (32) of responses concerning 'cleanliness of the community', which is a theme which has shown up previously as a candidate-determinant in both Circumstances (Xu et al., 2016; Li et al.; 2017) but has not yet been fully investigated for causal links. It is interesting in terms of social norms because this 'extra cleanliness' noted by residents from recycling has not been measured or documented by practitioners: it is a perceived cleanliness and thus possibly linked to normative expectations and desires - some kind of social norm. A specialised investigation would be needed to unpack the different possible elements.

Altogether, these results indicate that this is a rich area for further research, and in particular for a study which could distinguish between different types of social influences. Although this could be best designed with respect to specifically related socio-psychological theories and perspectives, e.g. as reviewed in Abrahamse and Steg (2013), from experience we would aim to design in significant opportunities for unexpected effects to emerge. From a grounded empiricism perspective, such a study could entail a repeat of the experiment described here, but with a very large number of focused and in-depth interviews in the vicinity of the deposit sites, immediately post-experiment.

\section{Conclusion}

This pragmatic study set out to determine the relative contributions of Habit, Social Influence and personal Incentives influencing directly-measured residential recycling behaviour in an established program in 5 experimental communities (each with 400-1600 households and 1-2 control communities) in Nanjing. Results show that, for programs established longer than 12 months, the incentives themselves contributed to less than $5 \%$ 
of the measured behaviour, and habit $80-90 \%$, but that a surprisingly large number - 10$20 \%$ - were significantly influenced by social influences. Although their nature was not specified in detail, they were linked to the attendance of participants to a designated place to claim their Green Points through an interpersonal interaction with a regular staff member, often in the presence of other participants.

Comparing programs established for only 10-11 months (to those $12-23$ months), the relative influences were: incentives 12\% (5\%); habit 50\% (80-90\%); social influence 50\% $(10-20 \%)$.

Such results at community scale are very useful for policy advice. They suggest that personal incentives could be reduced after 12 months, when habit is widespread - thus saving costs and helping the program towards long-term financial sustainability. (Further research would be needed to model accurately variations that might occur with different incentives involved, or the manner in which they are withdrawn). They also emphasise grounded results from other recent studies (Li et al.; 2017; Xu et al., 2016; Huang et al., 2018) which indicate that interpersonal interactions, or social influences related to them, might account for much of the recycling behaviour at the start of a program, continuing afterwards at a lower level. Assuming that habit is not only a determinant of good recycling behaviour but also the main target, these results show that social influences are over three times more influential than personal incentives, throughout the program - even though it is envisioned and perceived as an entirely 'incentives' program. This result calls for a reconsideration of the role of social influences in residential recycling programs, especially with respect to incentives, which might be cost-inefficient, and a deeper study into the source of the social influences involved, which might be easier to enhance on the ground.

Although these studies are based in China, there is no particular reason that the findings concerning the causal links are not generalisable, in the same way that other studies on behavioural determinants carried out in western countries are typically assumed to hold for humans elsewhere. Interestingly, once the importance of Interpersonal Interaction is repeatedly found as significant determinant in these China studies, the factor can be seen mentioned but not focussed upon in western studies such as a key meta-analysis of social influences for resource conservation (Abrahamse and Steg, 2013), and in a review of interventions for energy conservation (Abrahamse et al., 2005). Altogether, they suggest an urgent research agenda to determine the strength of the impact of interpersonal interaction 
on actual behaviour, because although it is counter-intuitive, pragmatically this may actually be more efficient than mass-delivery, in terms of overall cost-benefit analysis. This underpins the motivation for this study: to focus first on pragmatic need, to use researchthrough-design to pinpoint and test empirical determinants of a typology and then prescriptive theory. Later we can return to follow up the contributions of that empirical knowledge back into disciplinary theories e.g. of socio-psychology.

In addition, the study unexpectedly provided evidence that at least $10 \%$ of participants were inconvenienced by the restricted time window normally permitted for depositing (79 am). It seems they overcame this under normal operating periods, for social or incentives reasons: the number was larger at $20 \%$ in less-established programs (Figure 8 ). This size indicates that the role of inconvenience in deterring others from ever joining the program should be considered seriously by planners concerned about uptake, and further investigated in research.

These results all contribute soundly to the ongoing Stage 2 development of a general grounded Prescriptive Theory for residential recycling, which will ultimately be applicable in different cities and communities. Generalisable causal links are established for Incentives, Social Influences (including Interpersonal Interactions) and Habit, and raising the profile of Inconvenience. But the results also indicate rich areas for discipline-based research for theories from socio-psychology and economics. For example, on the changing interplay of social versus incentives influences as programs (and habit) becomes more established, or incentives versus time-inconvenience. As the Prescriptive Theory is consolidated with further Stage 2 experiments, and refinements of its typology, a well-evidenced agenda for systematic studies across recycling will continue to emerge which will be able to continue to assist city planners to design predictably successful recycling programs.

\section{References}

Abrahamse, W., Steg, L., Vlek, C., Rothengatter, T., 2005. A review of intervention studies aimed at household energy conservation. J. Environ. Psychol. 25 (3),273-291.

Abrahamse, W., Steg, L., 2013. Social influence approaches to encourage resource conservation: a meta-analysis. Glob. Environ. Change 23(6), 1773-1785. 
Allcott, H., and Mullainathan, S., 2010. Behaviour and Energy Policy. Science. 327,12041205.

Ajzen, I., 1991. The theory of planned behavior. Organ. Behav. Hum. Decis. Process.50, $179-211$

Archer, B., 1995. The nature of research. CoDesign: Interdisciplinary J. Design. 2, 6-13.

Barr, S., Ford, N.J., Gilg, A., 2003. Attitudes towards recycling household waste in Exeter, Devon: quantitative and qualitative approaches. Local Environ. 8 (4), 407-421.

Barr, S., Gilg, A.W., 2005. Conceptualising and analysing household attitudes and actions to a growing environmental problem: Development and application of a framework to guide local waste policy. Appl. Geogr. 25, 226-247.

Bi, X.C., 2020. Residents' community participation under the mode of single center intervention: the dilemma of urban domestic waste classification and its solution. Ningxia Soc. Sci. 4, 114-122.

Bernstad, A., la Cour Jansen, J., Aspegren, A. 2013. Door-stepping as a strategy for improved food waste recycling behaviour - Evaluation of a full-scale experiment. Resour. Conserv. Recycl. 73, 94-103.

Bowman, N., Goodwin, J., Jones, P., Weaver, N. 1998. 'Sustaining Recycling: Identification and Application of Limiting Factors in Kerbside Recycling Areas', Int. J. Sustain. Dev. and World Ecol. 5: 263-76.

Cheng, H., Hu, Y., 2010. Municipal solid waste (MSW) as a renewable source of energy: current and future practices in China. Bioresour. Technol. 101, 3816-3824.

Christensen, C.M., and Carlile, P.R., 2009. Course research: Using the case method to build and teach management theory, Acad. Manag. Learn. Educ. 8(2), pp. 240-251.

Carlile, P.R., Christensen, C.M., 2006. The Cycles of Theory Building in Management Research. Working Knowledge, Harvard Business School. Retrieved from http://hbswk. Christensen, C. M., and Raynor, M. E., 2003. Why hard-nosed executives should care about management theory. Harvard Business Rev. 81, 66-74. 
Comber, R., and Thieme, A., 2013. 'Designing beyond Habit: Opening Space for Improved Recycling and Food Waste Behaviours through Processes of Persuasion, Social Influence and Aversive Affect'. Personal and Ubiquitous Comput. 17 (6), 1197-1210.

Cox, J. 2004. Household Waste Behaviour in London Phase 2: High, Medium and Low Recyclers: attitudes, behaviour and needs. UK: Brook Lyndhurst.

Dahab, D.J., Gentry, J.W., Su, W., 1995. New ways to reach non-recyclers: an extension of the model of reasoned action to recycling behaviours. NA-Adv. Consum. Res. 22, 251256.

Dai, Y.C., Gordon, M.P.R., Ye, J.Y., Xu, D.Y., Lin, Z.Y., Robinson, N.K.L., Woodard, R., Harder, M.K., 2015. Why doorstepping can increase household waste recycling. Resour. Conserv. Recycl. 102, 9-19.

Dai, Y.C., Lin, Z.Y., Li, C.J., Xu, D.Y., Huang, W.F., Harder, M.K., 2016. Information strategy failure: personal interaction success, in urban residential food waste segregation. J. Clean. Prod. 134, 298-309.

Davies, J., Foxall, G.R., Pallister, J. 2002. Beyond the intention-behaviour mythology: an integrated model of recycling. Mark. Theory. 2, 29-113.

Defra, 2007. Waste Strategy for England 2007. The Stationary Office Ltd, London.

Edenhofer, O. Climate change 2014: mitigation of climate change, Vol. 3 (Cambridge Univ. Press, 2015).

EPA. 2019. Annual Report on the Prevention and Control of Solid Waste Pollution in Large and Medium-sized Cities in 2018.

http://www.mee.gov.cn/hjzl/sthjzk/gtfwwrfz/201901/P020190102329655586300.pdf

Eppel, S., Sharp, V., Davies, L., 2013. A review of Defra's approach to building an evidence base for influencing sustainable behaviour. Resour. Conserv. Recy., 79, 30-42.

Evans, D., 2012. Beyond the throwaway society: ordinary domestic practice and a sociological approach to household food waste. Sociology. 46, 41-56.

Evans, D., 2014. Food Waste: Home Consumption, Material Culture and Everyday Life. London: Bloomsbury Academic. 
Fan, B., Yang, W., Shen, X., 2019. A comparison study of 'motivation-intention-behavior' model on household solid waste sorting in China and Singapore. J. Clean. Prod. 211, 442454.

Frayling, C., 1993. Research in Art and Design [Royal College of Art Research Papers].1(1), London, R. Coll. of Art.

Garcés, C., Lafuente, A., Pedraja, M., Rivera, P., 2002. Urban waste recycling behavior: antecedents of participation in a selective collection program. Environ. Manage. 30, 378390.

Geiger, J., Steg, S., van der Werff, E., Berfu Ünal, A., 2019. A meta-analysis of factors related to recycling. J. Environ. Psychol. 64, 78-97.

Geislar, S., 2017. 'The New Norms of Food Waste at the Curb: Evidence-Based Policy Tools to Address Benefits and Barriers'. Waste Manag. 68, 571-580.

Gordon, M., 2015. A framework to allow intervention design to increase food waste recycling in an urban community in Shanghai. Masters Thesis, School of Environment and Technology. University of Brighton, Brighton UK.

Guagnano, G. A., \& Stern, P. C. (1995). Influences on attitude-behavior relationships. A natural experiment with curbside recycling. Environment and Behavior, 27(5), 699-718.

Hage, O., S $€$ oderholm, P., Berglund, C., 2009. Norms and economic motivation in household recycling: empirical evidence from Sweden. Resour. Conserv. Recycl. 53 (3), 155-165.

Harder, M.K., Stantzos, N., Woodard, R., Read, A. 2008. Development of a new quality fair access best value performance indicator (BVPI) for recycling services. Waste Manag. 28(2), 299-309.

Harder, M., Woodard, R., 2007. Systematic studies of shop and leisure voucher incentives for household recycling. Resour. Conserv. Recycl. 51(4), 732-753.

Huang, W., Wang, J., Dai, X., Li, M., Harder, M. K. 2014. More than financial investment is needed: food waste recycling pilots in Shanghai, China. J. Clean. Prod. 67, 107-116.

Huang, Y., Tamas, P., Harder, M. 2018. Information with a smile - Does it increase recycling? J. Clean. Prod. 178, 947-953. DOI: 10.1016/j.jclepro.2018.01.006 
Huffman, A. H., Van Der Werff, B.R., Henning, J. B., Watrous-Rodriguez, K. 2014. When do recycling attitudes predict recycling? An investigation of self-reported versus observed behaviour. J. Environ. Psychol. 38, 262-270.

Ittiravivongs, A., 2012. Recycling as habitual behavior: the impact of habit on household waste recycling behavior in Thailand. Asian Soc. Sci. 8 (6), 74-81.

Jackson, T., 2005. Motivating Sustainable Consumption a Review of Evidence on Consumer Behaviour and Behavioural Change. A Report to the Sustainable Development Research Network, Survey. Centre for Environmental Strategies, p.170.

Knussen, C., Yule, F., 2008. 'I'm not in the habit of recycling': the role of habitual behavior in the disposal of household waste. Environ. Behav. 40, 683-702.

Li, C.J., Huang,Y.Y., Harder, M. K. 2017. Incentives for food waste diversion: exploration of a long term successful Chinese city residential scheme. J. Clean. Prod. 156, 491-499.

Lin, Z.Y., Wang, X., Li, C.J., Gordon, M.P.R., Harder, M.K., 2016. Visual prompts or volunteer models: an experiment in recycling. Sustainability 8 (5), 458.

McCarty, J., and Shrum, L.J., 1994. The recycling of solid wastes: personal values, value orientations, and attitudes about recycling as antecedents of recycling behavior. J. Bus. Res. 30(1), 53-62.

Meng, X., Tan, X., Wang, Y., Wen, Z., Tao, Y., Qian, Y., 2019. Investigation on decisionmaking mechanism of residents' household solid waste classification and recycling behaviors. Resour. Conserv. Recycl. 140, 224-234.

Perrin, D., Barton, J., 2001. Issues associated with transforming household attitudes and opinions into materials recovery: a review of two kerbside recycling schemes. Resour. Conserv. Recycl 33, 61-74.

Refsgaard, K., Magnussen, K., 2009. Household behaviour and attitudes with respect to recycling food wasteeexperiences from focus groups. J. Environ. Manage. 90, 760-771.

Seonaidh and Caroline, 2003. Reasons for non-participation in a kerbside recycling scheme. Resour. Conserv. Recycl. 39, 369-385. 
Schwartz, S. 1977. Normative Influences on Altruism. Adv. Exp. Soc. Psychol. 10, 222279.

Schwartz, S. H. and Howard, J. A. 1981. "A Normative Decision-Making Model of Altruism," In: P. J. Rushton and R. M. Sorrentino, Eds., Altruism and Helping Behavior: Social, Personality, and Developmental Perspectives, Lawrence Erlbaum, Hillsdale, 189211.

Steg, L., and Vlek, C., 2009. Encouraging Pro-Environmental Behavior An Integrative Review and Research Agenda. J. Environ. Psychol, 29, 309-317.

Stern, P.C., 2000. New environmental theories: toward a coherent theory of environmentally significant behavior. J. Soc. Issues 56 (3), 407-424.

Timlett, R.E., Williams, I.D., 2008. Public participation and recycling performance in England: a comparison of tools for behaviour change. Resour. Conserv. Recycl. 52, 622634.

Tonglet, M., Phillips, P. S. \& Read, A. D. 2004b. Using the Theory of Planned Behaviour to investigate the determinants of recycling behaviour: a case study from Brixworth, UK. Resources, Conservation and Recycling, 41, 191-214.

Tucker, P., Grayson, J. \& Speirs, D. 2000. Integrated effects of a reduction in collection frequency for a kerbside newspaper recycling scheme. Resources, Conservation and Recycling, 31, 149-170.

Wang, S., Wang, J., Zhao, S., Yang, S., 2019. Information publicity and resident's waste separation behavior: an empirical study based on the norm activation model. Waste Manag. $87,33-42$

Woodard, R., Harder, M., Bench, M., Philip, M., 2001. Evaluating the performance of a fortnightly collection of household waste separated into compostables, recyclates and refuse in the south of England. Resourc. Conserv. Recycl. 31(3), 265-284.

Varotto, A., Spagnolli, A. 2017. Psychological strategies to promote household recycling. A systematic review with meta-analysis of validated field interventions. J. Environ. Psychol. $51,168-188$.

Vencatasawmy, C.P., Öhman, M., Brännström, T., 2000. A survey of recycling behaviour in households in Kiruna, Sweden. Waste Manage. Res. 18 (6), 545-556. 
Xu, D.Y., Lin, Z.Y., Gordon, M.P.R., Robinson, N.K.L., Harder, M.K., 2016. Perceived key elements of a successful residential food waste sorting program in urban apartments: stakeholder views. J. Clean. Prod. 134, 362-370.

Zhang, B., Lai, K.-H., Wang, B., Wang, Z., 2019a. From intention to action: How do personal attitudes, facilities accessibility, and government stimulus matter for household waste sorting?. J. Environ. Manag. 233, 447-458.

Zhang, D.Q., Tanb, S.K., Gersbergc, R.M., 2010. Municipal solid waste management in China: status, problems and challenges. J. Environ. Manage. 91(8), 1623-1633.

Zhang, Y., Xu, B., 2020. Research on the behavior of urban residents'garbage sorting based on the theory of embedded social structure. J. Arid Land R esour. Environ. 34(10), 64-70.

Zhuang, Y., Wu, S.W., Wang, Y.L., Wu, W.X., Chen, Y.X., 2008. Source separation of household waste: a case study in China. Waste Manage. 28, 2022-2030. 